\title{
2
}

\section{The Extended Enterprise - A Context for Benchmarking}

\author{
J. Browne ${ }^{\mathbf{a}}$, P.J. Sackett ${ }^{\mathbf{b}}$ and J.C. Wortmann ${ }^{\mathrm{c}}$ \\ ${ }^{a}$ CIMRU, University College, Galway. \\ ${ }^{b}$ CIMI, Cranfield University \\ ${ }^{c}$ Eindhoven University
}

\section{INTRODUCTION}

In his introduction to the 1992 European Manufacturing Futures Survey, De. Meyer suggests that manufacturing must "see itself as a link in an integrated value added chain, whose goal is to serve the customer" (my emphasis). Coming from a very different perspective, namely that of environmentally benign production, Tipnis (1993) also suggests a similar view when he subtitles his paper "How to design products that are environmentally safe to manufacture/assemble, distribute, use, service/repair, discard/collect, disassemble, recover/recycle and dispose?".

It is clear that the manufacturing function must look beyond "the four walls of the manufacturing plant". Global competition and the emerging pressures to develop environmentally benign products and processes, force manufacturing professionals to take a broader view. We term this broader view the "Extended Enterprise" and we believe that it provides the context within which Benchmarking takes place. In this paper we explore the concept of the Extended Enterprise and show how benchmarking can be an important tool to drive performance in the Extended Enterprise.

\section{WHAT IS BENCHMARKING?}

According to the PA Consulting Group, quoted in Kleinhans, Merle and Doumeingts (1994) "Benchmarking is the ongoing task, at all levels of our business, of finding and implementing world best practice in the key things we do that deliver customer satisfaction". The question arises as to what constitutes customer satisfaction. In the past, customer satisfaction was seen in terms of a quality product, delivered on time and at the right price. Today the situation is somewhat more complex. Customers, influenced by access to global information and increasingly environmentally aware, are taking a more sophisticated view. Environmental regulations and consumer preference for "Green" products are forcing corporations to design products that are environmentally safe to manufacture, use and dispose of. (See Tipnis 1993). Companies 
now gain competitive advantage because customers prefer their "Green" products and processes. Thus when we talk about benchmarking, defining best or "world class" practice in manufacturing, we are not thinking in terms of manufacturing performance as measured by cost, due date or quality metrics, rather we must consider the total product life cycle, from concept through design and manufacture and on to distribution, end of life disposal or refurbishment and reuse.

An important issue in benchmarking is the definition of appropriate measures of performance. Measures of performance are important. Clearly they provide milestones against which performance can be evaluated. However, measures of performance also serve to influence, often times to direct behaviour. Therefore the measures of performance must reflect very well the objectives of the system they purport to measure. In the 1960 s and 1970s, the focus within manufacturing was on the cost of production. Labour productivity became an important measures of performance. Industrial companies, and indeed industrial economies benchmarked their performance in terms of labour productivity. In the 1980 s, the emphasis shifted on to quality. Zero defects as suggested by Japanese customers, became the benchmark. Today the appropriate measures are less clear. Certainly cost, quality and timely delivery are important performance measures against which industrial companies can benchmark. However, other issues, thrown up by global competition and the increased emphasis on environmental concerns must also be considered.

\section{THE EMERGENCE OF THE GLOBAL MARKET}

Changes in the international trading relationships, manufacturing and information technology and infrastructure developments are leading to the realisation of the global market. In the past, companies operated in local markets, were subject to local cost and pricing structures and competed with local competitors. In many cases companies were effectively restricted to local suppliers, since information on remote suppliers was unavailable. The communications and transport costs associated with doing business with distant suppliers and customers were prohibitive. Trading conditions, customs controls and tariffs provided further barriers to global trade.

In recent years, the transportation problem has been radically reduced through vastly superior infrastructure and more efficient forms of transport such as economical air freight for perishable goods. This has greatly reduced the importance of manufacturing products close to their point of consumption. Miniaturisation of many product has also contributed to this trend. Communications technology has provided the customer with the ability to choose among a far greater range of vendors, operating both locally and in distant locations. In response to customer demands, trade restrictions have been greatly reduced, evidenced most recently by the signing of the new GATT Agreement by over 100 countries in 1994 . 
Such changes have certainly led to pressures on industry. Competitors may operate from a radically different cost base existing in a different country or continent, with cheaper labour rates, and can therefore offer more attractive prices to the customer. Other firms may have a technological advantage, or an extensive marketing apparatus, and so on. Industry must therefore strive for both cost competitiveness and product differentiation in order to compete. Conversely, successful firms can be rewarded well with a greatly expanded market in which to sell their products. The increasing sophistication of products, and pressures to reduce costs through efficient manufacture, has also led to increases in the capital outlay required to manufacture them. This can restrict manufacture to those companies with large, often global, markets where sufficient product sales can cover such high initial expenditure. Smaller firms are increasingly outsourcing and sub-contracting to specialist firms who operate in a different part of the world.

\subsection{The Concept of Mass Customisation.}

Up to the mid-nineteenth century, manufacturing in so far as it existed at all was confined to the production of low value customised products - in effect craft production. With the development of hard automation (the transfer line etc.) the age of mass produced standard products began. The relatively low cost of such products allowed significant proportions of the population of the western world to acquire consumer goods. As the technology of automation and mass production developed further, costs were further reduced. The development of information technology, and it's application to manufacturing technology in the 1960s and 1970s changed everything. Automation based on information technology is inherently different to the older "hard" automation in that it is flexible. Computer based automation facilitates the production of a wider range of products in lower volumes economically. Today we are approaching the stage where "mass customisation" is becoming a reality.

Mass customisation requires significant alterations to the traditional organisational, human and technological support systems of an enterprise. Existing companies have for many years carried out "continuous improvement" programmes which aim at continuously improving the efficiency and quality of the manufacturing process, and gradually optimising that process by increasing flexibility, employee skills, eliminating waste, and so on. Those employees who were responsible for operating the process were encouraged to find methods of improving it, continuously, in small increments. It has been assumed by some companies that a natural progression from continuous improvement would lead to the process and human flexibility required to support mass customisation. However, a critical difference between these two approaches is that with continuous improvement the product is stable, employees can assume this is what the customer requires. With mass customisation, the product specification cannot be taken for granted. 
Mass customisation requires a dynamic network of relatively autonomous units. Each unit handles a specific process or task, such as manufacturing a particular component, or performing a particular type of assembly. These units are not linked together in a serial manner. They are organised to be able to link together in any sequence which may be required to satisfy a customers requirements.

This approach implies a fundamental change in the way an enterprise plans for the future. Rather than ensuring it has the capability to produce a limited range of products quickly, efficiently and with zero defects, it must plan to produce any product variation the customer requires. Therefore, product and process design must concentrate on not only a limited number of known products, but on the capabilities required to design and manufacture customised products as required.

\subsection{The Environmental Imperative.}

Society is putting pressure on manufacturers, in order to create production systems which are neutral with respect to the environment. This pressure acts through government regulations and customer requests. It may take the form of legal regulations, economic and marketing requirements. These pressures constitute a challenge for companies, to develop new technology and materials. In the long run, environmentally benign production may become a competitive edge. Environmentally benign production requires a shift of paradigm for engineers, accountants, government agencies, and many other parties. There is one line of development which is clearly emerging from the environmental requirements for manufacturing as a system: the object of study should not be restricted to a single plant or production facility, but should include chains or networks of production and physical distribution. Issues such as design for recycling, refurbishment, environmental costing, and many legal issues can only be studied if the scope of study is enlarged to the chain of value-adding activities, including ultimately, end of life disassembly and refurbishment.

Today progressive manufacturing companies are developing a total life cycle approach to their products. One multinational supplier of telecommunications equipment and services to the European market has developed a "Product Life Cycle Management" program which currently includes six major activities, namely: design and technology, purchasing of supplies and materials, manufacturing processes, waste reduction and energy management, packaging and post consumer materials management. This company now includes environmental considerations as part of it's supplier qualification process. The "post consumer materials management" activity represents a long term challenge but is based on the following ideas : in the near future, manufacturing will refurbish and reuse products and recycle as much of their contents as possible; finally companies will source new markets for the recycled material and safely dispose of residual materials when necessary. 
For some manufacturing companies the "recycle, refurbish and resale" process has already begun. A recent article in the Economist (October < > November 5th, 1993, Page 99) reported that a UK company is producing and selling recycled and reconditioned motorcycles.

A major European based computer manufacturer has developed a "Design for Sustainable Development" programme. This programme was developed in the early $1990 \mathrm{~s}$ in response to three external influencing factors viz, emerging international legislation, the need to maintain and increase customer satisfaction and finally in an attempt to secure competitive advantage in the market. This company found that certain key customers were refusing to purchase consumables from it until it had implemented a return process. (Examples include laser printer toner kits). Furthermore, other customers were requiring the reuse and return of product accessories in order for the company to qualify as a key supplier. The company is convinced that it will develop a competitive advantage over it's rivals through it's "Design for Sustainable Development" programme. This programme focuses on "waste management", through waste reduction at source, design for disassembly and maximising the opportunity to recover materials through reuse, recycling, reclamation, resale, reconditioning and re manufacturing. This company has already developed a "Waste Management" infrastructure, which includes an operating special purpose facility in Europe to take back computers from key customers and recycle, reclaim, refurbish and resell them.

Alting (1993) suggests that the research and developments community will have to come up with a life-cycle concept, which individual companies can use to tailor their own specific concepts. Based on this life-cycle concept guidelines must be developed for each of the phases, that is design for environmentally and occupational health friendly production, distribution, usage and disposal/recycling. The important point that we can no longer see manufacturing as an end in itself; rather as one in a long chain of value adding activities. Figure 1 outlines this perspective.

Tipnis makes reference to the "expanded responsibility" of the manufacturer over the entire life cycle and talks about the design of products for sustainability. In his view design for sustainability provides specific targets for design for manufacture, assembly, service, disassembly, and recycling. Again we have evidence of the expanding role of the manufacturing $<\sim>$ beyond the four walls of the manufacturing plant.

We must also recognise the pressure of legislation forcing industrial companies to take responsibility for the environmental impact of the products and processes.

In Europe, the Council of the European Union has issued several directives regarding the environmentally sound production, distribution, use and disposal of products. These directives include the principles of the civil liability of the manufacturer for 


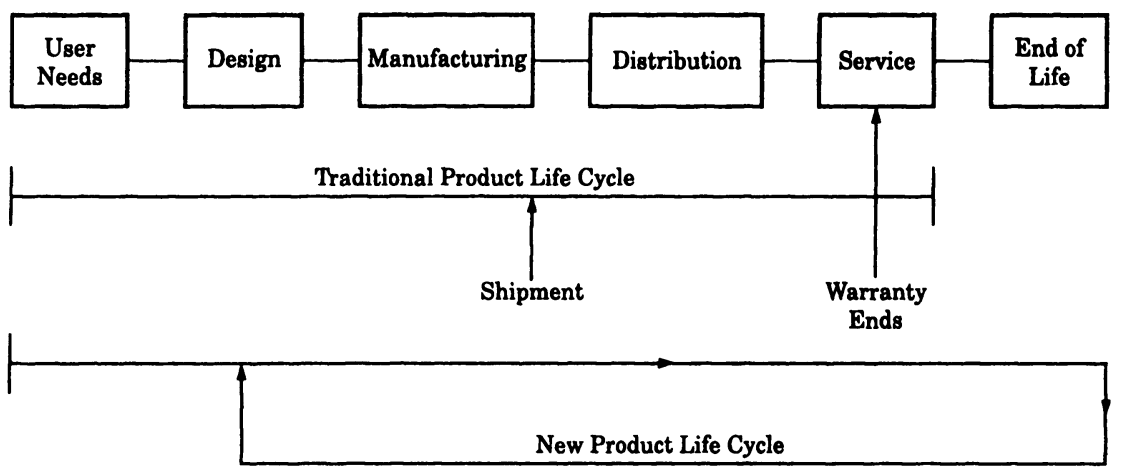

Fig. 1 Product Life Cycle as Seen by Producer

environmental damage caused by their products, financial incentives to achieve effective protection of the environment such as taxes on the use of damaging materials (for example Cholor-Floro-Carbons < > CFCs), material disposal charges, independent environmental audits and charges on non-biodegradable materials such as certain plastics. It is likely that in the near future manufacturers will be required to recycle obsolete products themselves or face high public disposal charges.

In Germany, government ordinances have been produced covering electronic waste regulation. These require that the manufacturer takes back all electronic equipment produced. If they have no recycling programme in place, then they are forced to bear the cost of "stockpiling" themselves, or pay large landfill charges. There is also legislation in place which requires that all plastic parts are marked to International Standards Organisation (ISO) 1042 standard which will facilitate recycling in the future.

In the United States, government bodies have defined recycling goals, source material and energy reduction goals, incentives for take back programmes, and credit for existing programmes. Certain taxes already exist to discourage the emission of toxic waste. The Environmental Protection Agency (EPA) provides a product life-cycle assessment service, which can be used by manufacturers to pinpoint the occurrences and causes of environmental pollution in the life of their products. Individual states have also determined requirements for recycling and usage bans on specific materials and components.

\section{THE EXTENDED ENTERPRISE}

How can a manufacturing company respond to the pressures placed on it by global competition? In the past the response was to make the factory more efficient and 
responsive by developing CIM (Computer Integrated Manufacturing) solutions. Now, however, the challenge is greater and requires that a degree of integration takes place across the whole value chain. The United States Department of Defence initiative, CALS $<\sim>$ Computer-aided Acquisition \& Logistics Support, has recognised this.

It is likely that, together with the European initiatives, CALS will influence the standards and the pace for inter organisation technical communication. The market place to which manufacturing businesses, business integration researchers, their teaching and their facilities must respond includes:-

- Business processes which cross enterprise boundaries to interface with functional areas in other companies, for example, product design or manufacturing process definition.

- Supplier/customer integration (people and processes) through interchange of commercial/technical data.

- Ability to function effectively as links for information and product in unbuffered supply/distribution chains.

The ability to network the activities of a number of entities to produce and sell manufactured products profitably depends on the relationship of these entities and the communication that passes between them (figure 2).

We are accustomed to thinking about this in the context of a single enterprise with different departments, Sales, Design, Engineering, Manufacturing, Distribution etc. However, within a global market-place, entities from many different enterprises, or entities which in themselves are nominally independent enterprises, relate via a single product to produce a designed result. An example might be a merchandising entity recognising a business opportunity and requesting :-

- a design entity to design it;

- a manufacturing entity to build it;

- a distribution entity to distribute it and;

- a marketing entity to sell it.

The implication of such an example is that all the entities can be considered as "flexible" or "programmable" within their expertise envelope. 


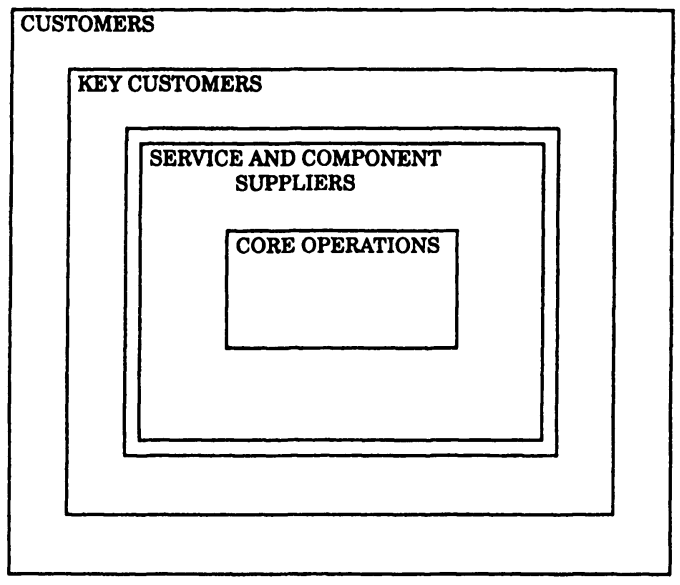

Fig. 2 The Extended Enterprise

We must also recognise that developments in computing and telecommunications facilitate the realisation of the networked Extended Enterprise. Referring to electronic data interchange and to the emerging integration of computing and telecommunications technologies, Keen uses the terms "Reach" and "Range". Reach is the extent to which one can interact with other communication nodes $\langle\sim>$ in the limit it becomes anyone, anywhere. Range defines the information types that can be supported from simple messaging between identical platforms to any computer generated data between any operating platforms (figure 3). Electronic mail available to all members of a single department offers the lowest level of technology integration. Until recently, extending reach across other parts of the company and particularly beyond the company has been both technologically difficult and expensive.

Extending range requires a good definition of business processes. Tools and organisational attitudes are now becoming available that make range extension viable. The driving force is the enhancement of business degrees of freedom to respond to the volatile market place. The level of change in the market place requires that we have flexibility not only in product but in business structure and business processes. A high level of reach and range provides the business freedom to operate in the Extended Enterprise. The mapping of a company onto the range/reach chart gives a good indication of its scope for innovative business improvement through the use of integration technologies (figure 4). In the Extended Enterprise the bringing together of core competencies from many different organisations to provide a short manufactured life product means regular enterprise business process restructuring. The pressure on time scales means interactive decision support is required. Companies without appropriate reach and range will not be able to participate in this Extended Enterprise 


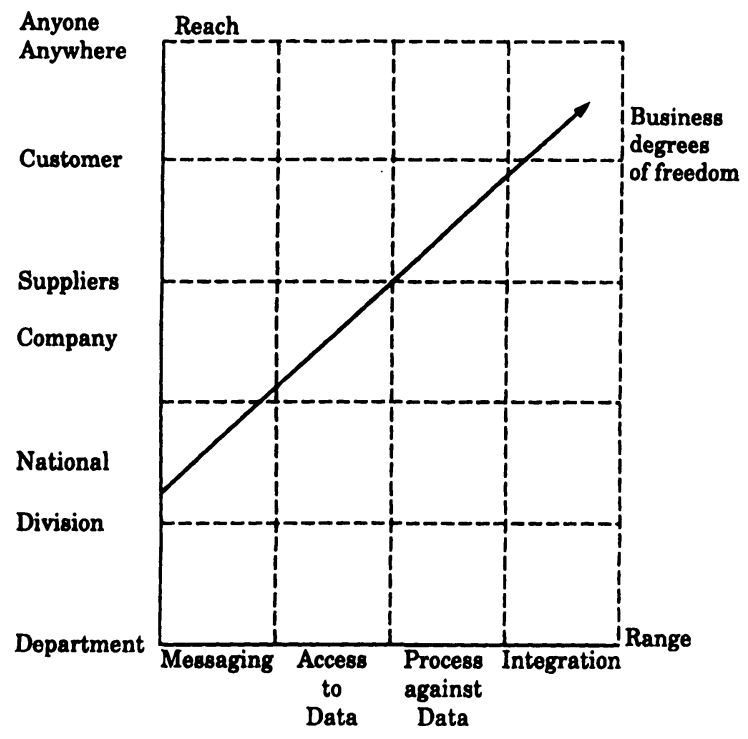

Fig. 3 Business and Technology Integration

business system. Technology integration price/performance improvements will greatly reduce price entry barriers to all companies world wide. In the past high reach/range has been recognised as valuable but has been only available in specialist applications.

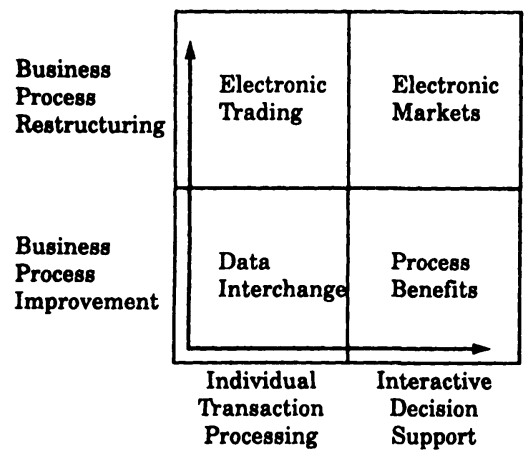

Fig. 4 Scope for Business Improvement through Integration 


\section{BENCHMARKING AND THE EXTENDED ENTERPRISE}

The institutionalisation of the Extended Enterprise will have far reaching outcomes. This will involve major structural change in business organisation. The basis of partnership within the Extended Enterprise is not yet well understood but alternative operations models are likely to be industry and market sector specific. Concurrent Engineering is becoming accepted but understanding of best practice on how, when and in what order to implement it is needed. The extension of tools to embrace environmental issues could offer significant benefit to small and medium sized enterprises. Organisational learning realisation offers the utilisation of industy's most significant business resource, its highly educated labour force. This will involve a re-assessment of the value of knowledge and the development of organisation based tools to use it. The appraisal of manufacturing business options must be developed to match the changes in the business operations environment described previously. Manufacturing information systems need to provide task defined specific solutions embracing emerging multimedia advances.

In Figure 4 we suggested that the development of electronic trading and indeed electronic markets will require business process restructuring. Already we see examples of this happening. The advanced use of EDE (Electronic Data Exchange) and EDI (Electronic Data Interchange) systems has fundamentally changed the nature of the interaction between many large customers (say final assemblers) and their component suppliers. Completely new ways of doing business have been developed. The authors are aware of one example where a component supplier sends his dispatcher to the site of his customer (a major telecommunications systems assembler) to identify the customers needs for components and is paid for these components based on the quantity of finished products shipped by the customer to his customers! Certainly this is an example of the "Extended Enterprise" in practice. It also indicates the need to redesign business processes to cope with the new reality. The redesign of business processes in turn is aided by the use of benchmarking which allows a manager or analyst to understand the potential for improvement in his own process by comparing them to world class and best practice.

\section{CONCLUSIONS}

In this paper, we have considered the emergence of the Extended Enterprise as a response to the pressures now impinging on manufacturers. We considered these pressures in terms of the development of the global market and the need to develop environmentally benign processes and products. The Extended Enterprise represents a new way of doing business and requires that we redesign and reengineer appropriate business processes. Benchmarking can support this activity by allowing an understanding of best practice. The Extended Enterprise allows us to provide for local 
customers while meeting global standards. Benchmarking facilitates the identification of global standards.

\section{REFERENCES}

1 Browne, J., Sackett, P.J., Wortmann, J.C., "The System of Manufacturing: A perspective study", Study for DGXII of the EU, November, 1993.

2 Alting, L. "Life-Cycle Design of Products: A New Opportunity for Manufaçturing Enterprises", in "Concurrent Engineering: Automation, Tools \& Techniques", Editor: A. Kusiak, J. Wiley \& Sons, 1993.

3 Kleinhans, S., Merle, C., Doumeingts, G., "Determination of What to Benchmark: a customer - oriented methodology", IFIP WG 5.7 Working Conference on Benchmarking, Trondheim, Norway, June 1994.

4 Tipnis, V.J., "Evolving Issues in Product Life Cycle Design", Annals of the CIRP, Volume 42, No.1, 1993.

5 O'hEocha, C., "A Framework for Concurrent Engineering", Master of Engineering Thesis, U.C.G., 1994.

6 De Meyer, A., "Creating the Virtual Factory" - Report of the 1992 European Manufacturing Futures Survey", INSEAD, France, December, 1992.

7 Keen. P.G.W., "Shaping the Future : Business Design through Information Technology", Harvard Business School Press, 1991. 